\title{
Endocrine changes and clinical profiles in depression: I. The dexamethasone suppression test
}

\author{
S. P. CALLOWAY, R. J. DOLAN, P. FONAGY, V. F. A. DE SOUZA \\ ANDA. WAKELING
}

From the Academic Department of Psychiatry, Royal Free Hospital, London

syNOPSIS Hypothalamic-pituitary-adrenal axis function was investigated in 72 patients with primary depression. Forty-four per cent of the patients demonstrated abnormal suppression of their cortisol levels after a $1 \mathrm{mg}$ overnight dexamethasone suppression test. Patients with abnormal suppression ('non-suppressors') were not clearly distinguished from 'suppressors' by the commonly used diagnostic classifications. They did not appear to be more severely depressed, but they were more likely than the "suppressors" to be in-patients. Multivariate analysis of the data suggested that two clinical features were independently associated with non-suppression: the PSE syndromes of Slowness and General Anxiety. However, the association of these syndromes with non-suppression was relatively weak, indicating that the clinical significance of the dexamethasone suppression test is, as yet, unclear. The results raise doubts about the validity of using the dexamethasone suppression test as a diagnostic marker for a specific depressive syndrome.

\section{INTRODUCTION}

There has been considerable interest in the neuroendocrine changes associated with depression. Most of the research in this area has focusedprimarilyon the hypothalamic-pituitaryadrenal and hypothalamic-pituitary-thyroid axes. Recent interest has been stimulated by reports of abnormalities of the dexamethasone suppression test (DST) and thyrotropin-releasing hormone test (TRH-test) in patients with depression and the possibilities of using these tests as diagnostic aids. The present paper reports on the DST in a group of 72 depressed patients with clearly defined clinical characteristics. A subsequent paper will consider the results of the TRH-test in the same group.

Early investigation of the hypothalamicpituitary-adrenal (HPA) axis revealed that plasma and urinary cortisol levels, and cortisol production rate, tended to be high in depressed patients, with levels returning to normal on clinical recovery (Board et al. 1957; Gibbons \& McHugh, 1962; Sachar et al. 1973; Carroll,

\footnotetext{
I Address for correspondence: Dr S. P. Calloway, Academic Department of Psychiatry, Royal Free Hospital, Pond Street, London
NW3 2QG.
}

1976). More recent work has focused on dynamic tests to assess HPA function. Dexamethasone, a synthetic corticosteroid, inhibits ACTH and cortisol production by the negative feedback mechanism. There is normally suppression of endogenous cortisol production for 24-28 hours after a $1 \mathrm{mg}$ dose at night (Krieger et al. 1971). Several investigators have shown that some patients with depression fail to suppress cortisol levels after dexamethasone (Butler \& Besser, 1968; Carroll et al. 1968; Stokes et al. 1976). Carroll et al. (1976) demonstrated that there was early escape from suppression rather than absolute non-suppression. Subsequent studies with psychiatric and normal controls reported that this finding was relatively specific to patients with depression and that, in addition, the test reverted to normal on clinical recovery (Carroll et al. 1981). The proportion of depressed patients who are 'non-suppressors' has been found to vary between 24\% (Holsboer et al. 1980; Amsterdam et al. 1982) and 69\% (Nuller \& Ostroumova, 1980).

Carroll (1982), reporting on the use of the DST in over 400 subjects, found that about $50 \%$ of patients with an 'endogenous' depressive profile showed non-suppression. However, attempts to 
use the DST as a diagnostic marker for endogenous depression have produced conflicting results. Some studies have found that the test was effective in distinguishing 'endogenous' from 'non-endogenous' depression (Carroll et al. 1981; Holden, 1983); however, this finding was not confirmed in other studies (Holsboer et al. 1980; Davis etal. 1981; Targum et al. 1982; Berger et al. 1982).

Inconsistency across the studies relating to the clinical features associated with non-suppression may be related to a number of factors: lack of strict diagnostic criteria, poor definition of patient groups, possible effects of drugs (Butler et al. 1968; Platman \& Fieve, 1968; Langer et al. 1979; Beary et al. 1983), physical illness in the patient groups (Murray, 1967; Brown et al. 1979), and failure to account for the relationship between non-suppression and certain clinical variables such as anxiety. Early investigators reported that anxiety symptoms were particularly associated with cortisol hypersecretion (Gibbons et al. 1960; Sachar et al. 1970; Stokes et al. 1976). This relationship may have been obscured in some recent studies by the inclusion of patients who were on drugs (e.g. Brown \& Shuey, 1980; Aggernaes et al. 1983). Psychotropic drugs not only affect endocrine function but also mental state, thus obscuring possible relationships between endocrine status and symptom profiles. Admission to hospital, environmental and psychological stresses have also been shown to affect the HPA axis (Sachar, 1967; Mason,

The aim of this study was to investigate the significance of the DST in drug-free patients with primary depression who had been carefully screened for physical illness and to determine the clinical features associated with non-suppression.

\section{METHOD}

\section{Patients}

The patients were admitted to the study from several sources: a psychiatric hospital, a district general/teaching hospital (in-patients, outpatients, Accident/Emergency), a psychiatric day hospital, and directly from general practice. One hundred and thirty patients were interviewed over a 2-year period; those with physical illnesses, secondary depression, or in whom it was considered unethical to internupt or delay treatment were excluded from the study. Patients over the age of 70 were also excluded from the exclusion criterial those who met any of Carroll's (Carroll, 1980). The remaining 80 the DST met the Research Diagnostic Criteria (RDC) all depression (Spitzeret al.1978) and were for a minimum period of and weredrug-free endocrine investigations of one week before some patients placebo medication out. In night, and 13 patients $(16.2 \%)$ recen was given at of temazepam at night. These 13 patients $10-20 \mathrm{mg}$ a very slight, non-significant trend showed higher cortisol output than the rest of towards there were no other differences an the group; were included in the investigations.

of the 80 patients ingations.

excluded from the received alternative psychiatric diagnoses 8 follow-up (one schizophrenia, two on affective, one anorexia nervosa, two schizodisease). Of the remaining nervosa and one Pick's found to have a remaining 3 patients, one was one developed brain tumour following CT scan, complete primary the investigations. Only patients with These 72 patients were RDC as Major Depressive by means of the Probable Major Depressive Disorder (9) and Minor Depressive Disorder (9). There were 64

\section{Table 1. Clinical features of patient group $(N=72)$}

\begin{tabular}{lc}
\hline Demographic & \\
Age (years) (mean IS.D.) & $41 \cdot 6 \pm 13 \cdot 7$ \\
Sex: female & $43(59 \cdot 7)$ \\
In-patient & $28(38 \cdot 9)$ \\
Previous history & $3 \cdot 7 \pm 2 \cdot 8$ \\
Previous episodes (mean tS.D.) & $20(27 \cdot 8)$ \\
Presenting with first episode & $32 \cdot 9 \pm 15 \cdot 4$ \\
Age of onset of first episode (mean tS.D.) & \\
Previous treatment & $32(44 \cdot 4)$ \\
Tricyclic antidepressants & $8(11 \cdot 1)$ \\
MAOIs & $27(37 \cdot 5)$ \\
Benzodiazepines & $6(8 \cdot 3)$ \\
ECT & $20 \cdot 4 \pm 7 \cdot 1$ \\
Hamilton score (mean \pm S.D.) & \\
CATEGO classes & $6(8 \cdot 3)$ \\
Depressive psychosis & $33(45 \cdot 8)$ \\
Retarded depression & $29(40 \cdot 3)$ \\
Neurotic depression & $2(3 \cdot 0)$ \\
Anxiety neurosis & $1(1 \cdot 4)$ \\
Paranoia & $1(1 \cdot 4)$ \\
Obsessional neurosis & \\
\hline &
\end{tabular}

The table shows the number of patients, with the percentages in parentheses. 
unipolar and 8 bipolar cases. On the basis of the Newcastle Diagnostic Index 36 patients $(50 \%)$ were classified as 'endogenous' and $36(50 \%)$ as neurotic. Thirty-five of the patients $(48.6 \%)$ were classified as 'endogenous', using the Discriminant Index of Feinberg \& Carroll (1982). Clinical and demographic features are shown in Table 1. Using the PSE Index of Definition (ID) (Wing et al. 1978), 70 of the 72 patients met the criteria of 'caseness' (an ID of 5 or more) and the remaining 2 patients had an ID of 4 . The distribution by CATEGO classes is also shown in Table 1.

\section{Clinical assessment}

After the initial interview and physical examination, haematological and routine biochemical investigations were performed, and all but 7 of the patients had an EEG. Clinical data included the Hamilton Rating Scale (Hamilton, 1967), the Newcastle Diagnostic Index (Carney et al. 1965), the Discriminant Index of Feinberg \& Carroll (1982), and the Present State Examination (PSE) (Wing et al. 1974). Close attention was paid to the course of illness, past history and family history. Family history data were collected from a family member where possible ( 64 cases). Data on the social variables were collected using the Bedford College Life Events and Difficulties Schedule (Brown \& Harris, 1978).

\section{Procedure}

A three-day 'acclimatization' period was allowed for in-patients before endocrine tests were performed, during which time the clinical interviews took place. In patients with extreme retardation the full interview was delayed until some clinical improvement had taken place. On Day 1 a 24-hour urine collection was taken from 11 p.m. to 11 p.m. the next day (Day 2), when $1 \mathrm{mg}$ of dexamethasone was given orally at 11 p.m., and a second 24-hour urine collection started. Blood was taken for plasma cortisols at 4 p.m. on Day 3. The first 24-hour urine was used to give the baseline cortisol production. The second 24-hour urine provided information on post-dexamethasone urinary free cortisol output which has been shown to be a good discriminator ofdepressed from non-depressed patients (Carroll \& Curtis, 1976). A TRH-test was performed on Day 4 or Day 5, and is described in the subsequent paper (Calloway et al. 1984). Out- patients made both 24-hour urine collections at home and came to the ward for the plasma sample, but 10 out-patients were admitted for short periods specifically for the study.

\section{Assays}

Cortisols in plasma and urine were measured in duplicate using a double antibody radioimmunoassay method (Amerlex Cortisol RIA kit). The coefficient of variation for repeated assays was $4.4 \%$. The normal range for 24 -hour urinary free cortisols using this method is $35-120 \mu \mathrm{g} / 24$ hours, although the upper range for this laboratory is taken as $130 \mu \mathrm{g} / 24$ hours.

\section{Analysis of results}

The patients were grouped according to the results of the DST or the TRH-test, and the mean levels of a number of endocrine variables were compared in these groups using one-way analysis of variance. Many of these variables appeared to have log-normal distributions; consequently, log transformations were performed before parametric statistical analyses were carried out. The associations between end ocrine variables were examined using Pearson product-moment correlations. The associations between patients grouped according to the results of the DST or TRH-test and the common diagnostic classifications were examined using chi-squared tests or Jonckheere's trend test (Leach, 1979), the latter being used in cases where the diagnostic groupings could be ranked. The significance of the normalized, corrected Kendall's $S$ statistic $\left(S_{\mathrm{c}}\right)$ is reported. The clinical features and scores on psychiatric rating scales of patients grouped according to the DST or TRH-test were compared, using one-way analysis of variance for continuous variables and chisquared tests for categorical variables. The large number of univariate statistical tests performed increased the likelihood of the analysis yielding false positive errors and this mandates caution in the interpretation of these results. In order to reduce the likelihood of obtaining significant effects by chance, two precautionary measures were taken whenever multiple univariate statistics were performed: first, variables which significantly correlated with one or more of the other variables were eliminated from the analysis; secondly, the level for rejecting the null hypothesis was increased to the $1 \%$ level of 
signifance. A step-wise discriminant function analysis (Jennrich, 1977) was carried out in an attempt to identify the clinical features which in combination could best identify patients with abnormalities on the DST or TRH-test.

\section{RESULTS}

(a) Urinary-free cortisols (UFC) and DST

Plasma cortisols were estimated on all 72 patients, pre-dexamethasone UFCs on 65 patients and post-dexamethasone UFCs on 70 patients. The mean pre-dexamethasone 24-hour UFC was $158.6 \mu \mathrm{g} / 24$ hours (S.D. $=77.8$, range $33-378$ ). Thirty-eight of the patients $(58.5 \%)$ had a 24-hour secretion above the normal range $(25-130 \mu \mathrm{g} / 24$ hours). The mean post-dexamethasone 24 -hour UFC was $65.4 \mu \mathrm{g} / 24$ hours (S.D. $=56.3$, range 6-232). The mean 4 p.m. plasma cortisol was $6.2 \mu \mathrm{g} / \mathrm{dl}$ (S.D. $=7 \cdot 0$, range $0 \cdot 5-35 \cdot 0)$. Using the $5 \mu \mathrm{g} / \mathrm{dl}$ cut-off point for non-suppression (Carroll, 1982), 28 patients were classified as 'non-suppressors'.

There were significant correlations between pre- and post-dexamethasone UFC levels $(r=0.708, \mathrm{df}=62, \quad P<0.001)$ and between post-dexamethasone plasma cortisol and postdexamethasone UFC levels $(r=789, \mathrm{df}=67$, $P<0.001)$. Using a linear regression function, the post-dexamethasone UFC value corresponding to a plasma level of $5 \mu \mathrm{g} / \mathrm{dl}$ was found to be $58.01 \mu \mathrm{g} / 24$ hours. The value of $58 \mu \mathrm{g} / 24$ hours was taken as a UFC cut-off point for nonsuppression. This resulted in 27 patients $(38.6 \%)$ being classified as 'non-suppressors'. The two methods of identifying 'non-suppressors' overlapped closely. Five patients identified as 'non-suppressors' by plasma levels fell into the 'suppressor' category as defined by UFC levels. Conversely, 4 patients identified as 'nonsuppressors' by UFC levels fell into the 'suppressor' category as defined by a plasma level of $5 \mu \mathrm{g} / \mathrm{dl}$. When results from both methods were taken together, 32 patients $(44.4 \%)$ were classified as "non-suppressors', and this group was used in the subsequent analysis. All but 2 of these patients met the more stringent criteria of having a 4 p.m. plasma cortisol above $6 \mu \mathrm{g} / \mathrm{dl}$ and/or a post-dexamethasone UFC above $75 \mu \mathrm{g} / 24$ hours. When the subsequent analyses were duplicated, using just the plasma cortisol values to define non- suppression, the results were essentially the same
as when the above criteria were used.

(b) Relationship between non-suppression and diagnostic categories of depression

The frequency of 'non-suppressors' in groups defined by current methods of classifying or There was a trend for shown in Table 2. appear with above chance frequencessors' to patients classified as definite Major Depressive Disorder on the RDC, and also among those classified as having definite or probable endogenous subtype of Major Depressive Disorder within this classification system. The proportion of 'non-suppressors' was similar in patients classified as endogenous and in those classified as neurotic by the Newcastle Diagnostic Index. Nevertheless, there was a trend for the endogenous category, as defined by Feinberg \& Carroll's Discriminant Index, to contain more 'non-suppressors' than 'suppressors'. The proportion of 'non-suppressors' was similar in the patient groups derived from the Iowa Classification (Winokur, 1979). When patients were grouped by PSE classes, 5 out of 6 patients classified under Psychotic Depression were 'non-suppressors'; $60.6 \%$ of patients in the Retarded Depression class were 'non-suppressors', compared with $24.1 \%$ of those in the Neurotic Depression class $\left(\chi^{2}=8.35, P<0.01\right)$.

\section{(c) Clinical features associated with the DST}

'The clinical features of 'non-suppressors' and 'suppressors' are shown in Table 3. Features not included in the table - such as height, weight and height/weight ratio - did not differ between the groups. There was no significant age difference between the two groups, although the 'nonsuppressors' tended to be older.

The presence or absence of long-term difficulties or major life events in the 6 months prior to onset did not differentiate the two groups. There was a significantly greater proportion of 'nonsuppressors' among in-patients in comparison with out-patients. This may have been due to hospitalization itself or to patient characteristics associated with a recommendation for admission. To examine this question, a sample of 10 patients who would normally have been seen and treated as out-patients were admitted for the duration of the tests, allowing the same 'acclimatization' 
Table 2. Number and percentage of 'non-suppressors' in various diagnostic sub-divisions of depression

\begin{tabular}{|c|c|c|c|c|}
\hline & \multirow[b]{2}{*}{$\begin{array}{l}\text { Total no. } \\
\text { of patients }\end{array}$} & \multicolumn{2}{|c|}{ 'Non-suppressors' } & \multirow[b]{2}{*}{ Statistics } \\
\hline & & No. & $(\%)$ & \\
\hline \multicolumn{5}{|l|}{ Research Diagnostic Criteria } \\
\hline (i) Definite & 54 & 28 & $(51 \cdot 8)$ & \\
\hline (ii) Probable & 9 & 2 & $(22 \cdot 2)$ & $S_{6}=267.8^{*}$ \\
\hline B. Minor depressive disorder & 9 & 2 & $(22 \cdot 2)$ & $P<0.05$ \\
\hline \multicolumn{5}{|l|}{ A. Endogenous depressive disorder } \\
\hline (i) Definite & 34 & 19 & $(55 \cdot 9)$ & \\
\hline (ii) Probable & 15 & 7 & $(46 \cdot 7)$ & $S_{c}=329 \cdot 3^{*}$ \\
\hline $\begin{array}{l}\text { B. Non-endogenous depressive disorder } \\
\text { Newcastle Diagnostic Index }\end{array}$ & 23 & 6 & $(26 \cdot 1)$ & $P<0.05$ \\
\hline A. Endogenous & 36 & 17 & $(47 \cdot 2)$ & $x^{2}=0.23 \uparrow$ \\
\hline & 36 & 15 & $(41 \cdot 6)$ & NS \\
\hline $\begin{array}{l}\text { A. Endogenous } \\
\text { A. }\end{array}$ & \multicolumn{4}{|c|}{ Discriminant Index (Feinberg \& Carroll, 1982) } \\
\hline B. Uncertain & 18 & 7 & $(38.9)$ & $S_{\mathrm{c}}=340 \cdot 5^{*}$ \\
\hline C. Non-endogenous & 19 & 5 & $(26 \cdot 3)$ & $P<0.02$ \\
\hline \multicolumn{5}{|l|}{ PSE classes } \\
\hline A. Depressive psychosis & 6 & 5 & $(83 \cdot 3)$ & \\
\hline B. Retarded depression & 33 & 20 & $(60 \cdot 6)$ & $x^{2}=11 \cdot 71 \uparrow$ \\
\hline C. Neurotic depression & 29 & 7 & $(24 \cdot 1)$ & $\ddot{P}<0.01$ \\
\hline Iowa Classification & 8 & 3 & $(37 \cdot 5)$ & $x^{2}=0.18 \dagger$ \\
\hline B. Unipolar & 64 & 29 & $(45 \cdot 3)$ & NS \\
\hline (i) Pure familial depressive disease & 18 & 10 & $(55 \cdot 5)$ & \\
\hline (ii) Sporadic depressive disease & 25 & 8 & $(32 \cdot 0)$ & $x^{2}=2.97 \dagger$ \\
\hline (iii) Depressive spectrum disease & 21 & 11 & $(52 \cdot 4)$ & NS \\
\hline
\end{tabular}

* Results of Jonckheere's test.

$\uparrow$ Results of chi-squared test.

Table 3. Clinical features of 'non-suppressors' $(N=32)$ and 'suppressors' $(N=40)$

\begin{tabular}{|c|c|c|c|}
\hline & 'Non-suppressors' & 'Suppressors' & Statistics \\
\hline Age (mean \pm S.D.) & $44 \cdot 3 \pm 14 \cdot 1$ & $39 \cdot 6 \pm 13 \cdot 4$ & NS \\
\hline Family history of depression $(\%)$ & $53 \cdot 1$ & $32 \cdot 5$ & NS \\
\hline \multicolumn{4}{|l|}{ Previous history (mean \pm S.D.) } \\
\hline Age at onset of first episode & $33 \cdot 5 \pm 16 \cdot 5$ & $32 \cdot 4 \pm 14 \cdot 6$ & NS \\
\hline Number of previous admissions & $1 \cdot 2 \pm 1 \cdot 7$ & $0.5 \pm 0.9$ & $F=4.31 ; \mathrm{df}=1,70 ; P<0.05$ \\
\hline \multicolumn{4}{|l|}{ Current episode } \\
\hline $\begin{array}{l}\text { Duration (months) (mean } \pm \text { S. D.) } \\
\text { In-patients }\end{array}$ & $8 \cdot 4 \pm 5 \cdot 1$ & $7 \cdot 4 \pm 7 \cdot 4$ & NS \\
\hline $\begin{array}{l}\text { In-patients }(\%) \\
\text { With major life events } \\
\text { or difficulties } \%\end{array}$ & $\begin{array}{l}59 \cdot 4 \\
56 \cdot 3\end{array}$ & $\begin{array}{l}22 \cdot 5 \\
52 \cdot 5\end{array}$ & $\begin{array}{l}\chi^{2}=8.68, P<0.005 \\
\text { NS }\end{array}$ \\
\hline
\end{tabular}

period as for the other in-patients. There was no difference between the cortisol output of this group when compared with the out-patient group, suggesting that the high proportion of "non-suppressors' in the in-patient group is due to their clinical status, rather than to admission per se.

Previous treatment, in the distant or recent past, was not associated with non-suppression. Of the 13 patients currently taking temazepam, 11 were clear-cut 'non-suppressors' $(N=7)$ or 'suppressors' $(N=4), 1$ was a borderline 'non-suppressor', and 1 a borderline 'suppressor'.

The mean scores of 'non-suppressors' and 'suppressors' on a number of rating scales and PSE syndromes are shown in Table 4. The Discriminant Index score was significantly higher for 'non-suppressors'. The PSE syndrome score which significantly differentiated between 'non-suppressors' and 'suppressors' was SL (Slowness), the PSE measure of retardation, 

Table 4. Scores (mean \pm S.D.) on psychiatric rating scales of 'non-suppressors' $(N=32)$
and 'suppressors' $(N=40)$

Statistics

Hamilton score

Newcastle score

Discriminant Index score

(Feinberg \& Carroll, 1982)

PSE score (total)

PSE syndrome scores

Slowness

General Anxiety

$\mathrm{ED}$

Non-suppressors
$21 \cdot 8 \pm 8 \cdot 5$
$5.8 \pm 2 \cdot 6$
$35.9 \pm 19 \cdot 5$
$29 \cdot 3 \pm 11 \cdot 8$
$1.72 \pm 2 \cdot 1$
$1.97 \pm 1 \cdot 46$
$1.25 \pm 1 \cdot 19$

'Suppressors'

$19 \cdot 2 \pm 5 \cdot 6$

$5 \cdot 3 \pm 2 \cdot 4$

$24 \cdot 5 \pm 12 \cdot 4$

$24 \cdot 4 \pm 8 \cdot 4$

$0 \cdot 55 \pm 1 \cdot 1$

$1 \cdot 25+1 \cdot 28$

$0.95 \pm 0.95$
NS

NS

$F=8.33 ; d f=1,70 ; P<0.01$

$F=4 \cdot 13 ; \mathrm{df}=1,70 ; P<0.05$

$F=8.24 ; \mathrm{df}=1,70 ; P<0.01$

$F=5.16 ; \mathrm{df}=1,70 ; P<0.05$ consisting of the symptoms of slowness and restriction of movement and speech. The difference in scores for GA (General Anxiety), which combines free-floating anxiety, panic attacks and observed anxiety, approached significance. The scores on other PSE syndromes, including ED (special features of depression), consisting of guilt, loss of affect, dulled perception, did not differ between the groups.

In order to determine which of the above features were most important in identifying a patient as either a 'non-suppressor' or a "suppressor', a stepwise discriminant function analysis was performed. In addition to the PSE syndrome scores, the total PSE score, Hamilton rating, Newcastle rating, and age were included in this analysis. Only two variables - the PSE syndromes of general anxiety and slowness - were selected by the procedure to be entered into the discriminant function. A jack-knifed classification was performed. ${ }^{1}$ Slowness was entered first and correctly classified $63.9 \%$ of the patients. The entry of General Anxiety into the discriminant function improved the number of patients correctly classified by four. The function based on values of Slowness and General Anxiety was able to classify $70.8 \%$ of patients $(64.3 \%$ of non-suppressors' and 75.0\% of 'suppressors').

There was no correlation between General Anxiety and Slowness $(r=-0.03)$, and they appeared to be relatively independent features defining non-suppression. This could suggest that there were two sub-groups within the 'non-suppressor' group. They were therefore arbitrarily divided into those who were predominantly retarded (Slowness of 2 or more,

The jack-knifed classification was performed by eliminating each case in tum to be classified from the computations of group means
and cross-products (Lachenbruch \& Mickey, 1968). or Slowness of 1 with GA of 0 or 1) and those manifesting predominantly anxious symptomatology (GA of 2 or more and Slowness less than 2, or GA of 1 with Slowness of 0 ). These two groups were compared on a variety of clinical variables. The results of this analysis did not show any major differences between the two groups. There was no relationship between the two subgroups and the PSE classes (D, R or N).

Life events in the 6 months prior to onset were equally prevalent in both groups. Agitation was present in both groups. The retarded 'nonsuppressors', however, had an older age at onset than the anxious 'non-suppressors' $(42 \cdot 2 \pm 18 \cdot 4$, compared with $27 \cdot 6 \pm 12 \cdot 4$ ); this difference was significant, using the Brown \& Forsythe (1974) statistic for unequal variances $(F=6 \cdot 26 ; \mathrm{df}=1$, $30 ; P<0.05)$.

\section{DISCUSSION}

This group of 72 patients who were drawn from a wide variety of sources, including general practice, showed a considerable degree of HPA axis disinhibition. Forty-four per cent of patients had abnormal suppression of cortisols after $1 \mathrm{mg}$ of dexamethasone, a figure comparable with that found in previous studies (Carroll, 1982).

The commonly used classificatory systems for depression did not identify accurately the patients with non-suppression. We found that about $50 \%$ of patients with 'endogenous' features of depression tended to be "nonsuppressors'. The retarded group on the PSE classification contained a similar proportion. However, $24 \%$ of patients classed as neurotic depression by the PSE and $41 \%$ of patients classified as neurotic by the Newcastle Scale were also found to be 'non-suppressors'. Similar 
findings have been reported by Holsboer et al. (1980), Berger et al. (1982) and Peselow et al. (1983), although Holden (1983) reported that patients with endogenous depression as defined by the Newcastle Scale were more likely to be 'non-suppressors' than those defined as neurotic.

There are several possible explanations for the discrepancies found in different studies. These include the assay techniques used, the nature of the patient population under investigation, the effects of medication and the means used to classify patients as 'endogenous' or 'neurotic", especially with regard to the presence or absence of precipitants.

Radio-immunoassay (RIA) techniques have been widely used for assaying plasma and urinary corticosteroids in endocrine studies in depression, but a competitive protein binding (CPB) method has been used in some studies, including that of Carroll et al. (1981). Wood et al. (1983) reported that different RIA kits gave different mean cortisol levels when a series of samples were assayed, although the results did correlate with each other. Meltzer \& Fang (1983) reported that, in general, RIA methods for assaying cortisols gave results which were about $25 \%$ greater than those obtained by CPB methods. Thus, patients identified as "nonsuppressors' by RIA cortisol measurement would not necessarily be classified as "nonsuppressors' by the CPB method. However, Meltzer \& Fang found a close correlation between the results obtained from the CPB method and those from the Amerlex RIA kit $(r=0.95)$, which is the kit used in the present study. The RIA method tended to give higher cortisol levels than the CPB method, with a mean difference between the assays of 0.79 $( \pm 1 \cdot 22) \mu \mathrm{g} / \mathrm{dl}$. However, the differences were more likely to occur with higher cortisol concentrations. These authors reported that only one sample which was assayed as being greater than $5 \mu \mathrm{g} / \mathrm{dl}$ on the CPB method was found to be less than $5 \mu \mathrm{g} / \mathrm{dl}$ on the Amerlex. RIA kit

Another recent study also found a close correlation between the results of the CPB and RIA methods for assaying cortisols (Wilens et al. 1983). In contrast to the findings of Meltzer \& Fang (1983), Wilens et al. reported that the RIA method gave results which were about $7 \%$ lower than those from the CPB method.
In the present study all but two of the patients who were 'non-suppressors' when the $5 \mu \mathrm{g} / \mathrm{dl}$ cut-off point was used had cortisol levels which fell above the $6 \mu \mathrm{g} / \mathrm{dl}$ cut-off point, and many had distinctly higher values. Moreover, the post-dexamethasone UFC levels provided confirmation for the plasma cortisol values. It is likely that nearly all the patients in this study would also have been classified as "nonsuppressors' had the CPB method been used, thus allowing valid comparisons to be made with the results of Carroll et al. (1981) and other studies.

Patient selection may also influence the results. In the present study it emerged that 5 out of 6 patients with psychotic symptomatology (delusions and/or hallucinations) were 'nonsuppressors', a similar proportion to that reported by Mendlewicz et al. (1982). The presence of a large number of psychotic patients in a population under investigation could result in a greater association between 'endogenous' depression and non-suppression than would occur in studies such as those of Amsterdam etal. (1982) which was performed on an out-patient population.

The effects of medication on patients' endocrine status and symptomatology must also be taken into account in view of the fact that many studies include patients on tricyclic antidepressants and/or tranquillizers. Depressed patients treated with psychotropic drugs may experience relief from anxiety before other symptoms of depression are alleviated. Such patients would then be more likely to be classified as having endogenous depression on the Newcastle Scale (because of the negative loading for anxiety) than if they had remained drug-free. Because some of these patients would be 'non-suppressors' (as shown in the present study), this could produce a bias towards an association between 'non-suppressor' status and endogenous depression. It is possible that the present study would have demonstrated a stronger association between anxiety and non-suppression if the 13 patients taking temazepam had received placebos instead.

A further possible source of bias arises from the method used to determine the presence or absence of precipitating life events which, in turn, influences whether someone is classified as endogenous or neurotic. The present study is the first in the field to have used the Bedford College 
Life Events and Difficulties Schedule (LEDS) to collect these data. This instrument provides a contextual rating of the severity of life events, and thus an objective assessment as to whether a significant precipitating life event is present or absent (irrespective of what the patient thinks to be significant). When a subjective assessment of the presence or absence of precipitants is used - as with the Newcastle Scale or Feinberg \& Carroll's Discriminant Index - it is possible that retarded or guilty patients would underreport precipitating events, being less likely to blame external circumstances for their plight. This could lead to an artificial association between endogenous symptomatology (retardation, guilt, etc.) and the absence of precipitants. Both the Newcastle Scale and the Discriminatory Index of Feinberg \& Carroll (1982) load negatively for 'endogenous' depression if a precipitating event is judged to be present. In this study, however, we found that patients with 'endogenous' features of depression were just as likely to have significant preceding life events as those with 'non-endogenous' features, a finding reported by previous authors (Goodwin \& Bunney, 1972; Hirschfield, 1981). 'Non-suppressors' were as likely as 'suppressors' to have experienced significant life events in the 6 months prior to onset. The Discriminant Index of Feinberg \& Carroll and the Newcastle Scale would have distinguished more effectively between 'non-suppressors' and 'suppressors' in this population if the negative loading for 'precipitants' had been excluded.

These results, taken in conjunction with those of previous studies, suggest that non-suppression is not restricted to any particular depressive syndrome. This suggests that the phenomenon may be due to non-specific processes occurring in depressed patients, more commonly in those patients with 'endogenous' symptomatology. Such processes may also occur in other conditions, as non-suppression has been reported in some patients with schizophrenia (Shulman \& Diewold, 1977), anorexia nervosa (Gerner \& Gwirtsman, 1981), bulimia nervosa (Hudson et al. 1982), dementia (Spar \& Gerner, 1982) and chronic 'psychogenic' pain (Blumer et al. 1982). Suwa et al. (1974), in a large study of HPA function in a heterogenous population of psychiatric patients, suggested that there could be two factors accounting for disinhibition of the
HPA axis: 'emotional turmoil' and 'disease processes involving certain areas of the central nervous system' (such as the temporal lobes).

In the present study there was no association between non-suppression and the severity of the depressed mood itself. Longitudinal studies on depressed patients have also found that changes in cortisol levels are not related to change in depressed mood as a symptom but to other features, such as anxiety (Gibbons et al. 1960; Sachar, 1967). Our findings suggested that two of the determinants of 'non-suppressor' status were retardation and anxiety. An association between 'non-suppressor' status and anxiety has also been reported by Stokes et al. (1976) and by Reus (1982). In addition, an association between non-suppression and retardation has been reported by Brown \& Shuey (1980) and by Agren \& Wide (1982).

As retardation and anxiety appeared to be independent factors discriminating "nonsuppressors' from 'suppressors', it is possible to speculate that there were two separate subgroups of patients with non-suppression: a predominantly anxious group, somewhat younger in age, with an earlier age of onset; and a predominantly retarded group, with later age of onset. It is possible that these differences between the two groups merely reflect a tendency for younger depressed patients to present with anxiety, while older patients present with retardation. However, the fact that later age of onset of first episode rather than older present age was associated with retardation is inconsistent with this, and suggests that there may be two subgroups of patients with non-suppression or, more likely two processes accounting for nonsuppression within any group of patients.

The two processes might represent quite different patterns of neurotransmitter dysfunction producing disinhibition of the HPA axis and non-suppression. The possibility that depressed patients who are 'non-suppressors' have different underlying neurotransmitter abnormalities has important implications for future research into aetiology and treatment. The failure of Greden et al. (1981) to replicate the reports of Brown et al. (1980) that 'non-suppressors' responded better to antidepressants with predominantly noradrenergic-uptake-inhibiting activity may, in part, be explained by the heterogeneity of the 'non-suppressor' group of depressed patients. 

use of the DST to identify any particular depressive syndrome as the abnormality occurred s the currently used diagnostic categories. These results suggest that there might be at least two different mechanisms, not necessarily mutually exclusive, accounting for non-suppression in depressed patients.

We would like to thank Dr A. Mann, Dr J.M. Kennedy, Professor G. W. Brown, Dr T. Harris, Dr T. Craig, Ms K. Wood, Dr A. Higgitt, Ms M. Hakda, Ms K. Scott and Ms L. J. Dunlop Humphrey for their help, also the staff of Nicol Ward and the Caversham Health Centre, Kentish Town, for their cooperation. This study was carried out while S. P. Calloway and R. J. Dolan were Wellcome Research Fellows.

\section{REFERENCES}

Aggernaes, H., Kirkegaard, C., Krog-Meyer, L., Kijne, B., Larsen, J. K. Laursen, A. L., Lykke-Olesen, L., Mikkelsen, P. L. Rasmussen, S. \& Bjørum, N. (1983). Dexamethasone suppression test and TRH test in endogenous depression. Acta Psychiatrica Scandinavica $67,258-264$

Agren, H. \& Wide, L. (1982). Patterns of depression reflected in pituitary thyroid and pituitary-adrenal endocrine changes. $P$ sychoneuroendocrinology $7,309-327$.

Amsterdam, J. D., Winokur, A., Caroff, S. N. \& Conn, J. (1982). The dexamethasone suppression test in out-patients with primary affective disorder and healthy control subjects. American Journal of Psychiatry 139, 287-291.

Beary, M. D., Hubert Lacey, J. \& Bhat, A. V. (1983). The neuro-endocrine impact of 3-hydroxy-diazepam (temazepam) in women. Psychopharmacology 79, 295-297.

Berger, M., Doerr, P., Lund, R., Bronisch, T. \& von Zerssen, D. (1982). Neuroendocrinological and neurophysiological studies in major depressive disorders: are there biological markers for the endogenous subtype? Biological Psychiatry 17, 1217-1242.

Blumer, D., Zorick, F., Heilbronn, M. \& Roth, T. (1982). Biological markers for depression in chronic pain. Journal of Nervous and Mental Disease 170, 425-428.

Board, F., Wadeson, R. \& Persky, H. (1957). Depressive affect and endocrine functions. Blood levels of adrenal cortex and thyroid hormones in patients suffering from depressive reactions. Archives of Neurology and Psychiatry 78, 612 .

Brown, G. W. \& Harris, T. (1978). Social Origins of Depression. Tavistock: London

Brown, M. B. \& Forsythe, A. B. (1974). The small sample behaviour of some statistics which test the equality of several means. Technometrics 16, 129-132.

Brown, W. A. \& Shuey, I. (1980). Response to dexamethasone and subtype of depression. Archives of General Psychiatry 37, 747-751.

Brown, W. A., Johnston, R. \& Mayfield, D. (1979). The 24-hour dexamethasone suppression test in a clinical setting: relationship to diagnosis, symptoms and response to treatment. American Journal of Psychiatry 136, 543-547

Brown, W. A., Haier, R. J. \& Qualls, C. B. (1980). Dexamethasone suppression test identifies subtypes of depression which respond to different antidepressants. Lancet i, 928-929.

Butler, P. W. P. \& Besser. G. M. (1968). Pituitary-adrenal function in severe depressive illness. Lancet ii, 1234-1236.

Butler, P. W. P., Besser. G. M. \& Steinberg, H. (1968). Changes in plasma cortisol induced by dexamphetamine and chlordiazepoxide given alone and in combination in man. Journal of Endocrinology $40,391-392$.

Calloway, S. P., Dolan, R. J., Fonagy, P., De Souza, V. F. A. \& Wakeling, A. (1984). Endocrine changes and clinical profiles in depression: II. The thyrotropin-releasing hormone test. Psychological Medicine 14, 759-765.

Carney, M. W. P., Roth, M. \& Garside, R. F. (1965). The diagnosis of depressive syndromes and the prediction of ECT response. British Journal of Psychiatry 111,659-674.

Carroll, B. J. (1976). Limbic system-adrenal cortex regulation in depression and schizophrenia. Psychosomatic Medicine 38, $106-119$.

Carroll, B. J. (1980). Clinical application of neuroendocrine research in depression. In Handbook of Biological Psychiatry, Vol. 3 (ed. H. M. Van Praag, M. H. Lader, O. J. Rafaelson and E. J. Sachar), pp. 179-193. Marcel Dekker: New York.

Carroll, B.J. (1982). The dexamethasone suppression test for melancholia. British Journal of Psychiatry 140, 292-304.

Carroll, B. J. \& Curtis, G. C. (1976). Neuroendocrine identification of depressed patients. Australian and New Zealand Journal of Psychiatry 10, 13-20.

Carroll, B. J., Martin, F. I. R. \& Davies, B. M. (1968). Resistance to suppression by dexamethasone of plasma 11-OHCS levels in severe depressive illness. British Medical Journal iii, 287.

Carroll, B. J., Curtis, G. C. \& Mendels, J. (1976). Neuroendocrine regulation in depression. I. Limbic system-adreno-cortical dysfunction. Archives of General Psychiatry 33, 1039-1044.

Carroll, B. J., Feinberg, M., Greden, J. F., Tarika, J., Albala, A. A., Haskett, R. F., James, N. McI., Kronfol, Z., Lohr, N., Steiner, M., De Vigne, J. P. \& Young, E. (1981). A specific laboratory test for the diagnosis of melancholia. Archives of General Psychiatry 38, 15-22.

Davis, K. L., Hollister, L. E., Mathe, A. A., Davis, J. M., Rothpearl, A. B., Faull. K. F., Hsieh, J. Y. K., Barchas, J. D. \& Berger, P. A. (1981). Neuroendocrine and neurochemical measurements in depression. American Journal of Psychiatry 138, 1555-1562.

Feinberg, M. \& Carroll, B. I. (1982). Separation of subtypes of depression using discriminant analyses. British Journal of Psychiatry $140,384-391$.

Gerner, R. H. \& Gwirtsman, H. E. (1981), Abnormalities of dexamethasone suppression test and urinary MHPG in anorexia nervosa. American Journal of Psychiatry 138, 650-653.

Gibbons, J. L. \& McHugh, P. R. (1962). Plasma cortisol in depressive illness. Journal of Psychiatric Research 1, 162-171.

Gibbons, J. L., Gibson, J. G., Maxwell, A. E. \& Wilcox, D. R. C. (1960). An endocrine study of depressive illness. Journal of Psychiatric Research 1, 162-171.

Goodwin, F.K. \& Bunney, W. E. (1973). A psychobiological approach to affective illness. Psychiatric Annals 3, 19-53.

Greden, J. F., Kronfol, Z., Gardner, R., Feinberg, M., Mukhopadhyay, S., Albala, A. \& Carroll, B. J. (1981). Dexamethasone suppression test and selection of antidepressant medications. Journal of Affective Disorders 3, 389-396.

Hamilton, M. (1967). Development of a rating scale for primary depressive illness. British Journal of Social and Clinical Psychology 6, 278-296.

Hirschfield, R. M. A. (1981). Situational depression: validity of the concept. British Journal of Psychiatry 139, 297--305.

Holden, N. L. (1983). Depression and the Newcastle Scale. Their relationship to the dexamethasone suppression test. British Journal of Psychiatry 142, 505-507.

Holsboer, F., Bender, W., Benkert, O., Klein, H. E. \& Schmauss, M. (1980). Diagnostic value of dexamethasone suppression test in depression. Lancet ii, 706.

Hudson, J. I. Laffer, P. S. \& Pope, H. S. (1982). Bulimia related to affective disorder by family history and response to the dexamethasone suppression test. American Joumal of Psychiatry $139,685-687$.

Jennrich, R. I. (1977). Stepwise discriminant analysis. In Statistical Methods for Digital Computers (ed. K. Enslein, A. Ralston and H. S. Wilf), pp. 76-95. Wiley: New York. 
Krieger, D. T., Allen, W., Rizzo, F. \& Krieger, H. P. (1971) Characterisation of the normal temporal pattern of plasma corticosteroid levels. Joumal of Clinical Endocrinology and Metabolism 32, 266-284.

Lachenbruch, P. \& Mickey, R. M. (1968). Estimation of error rates in discriminant analysis. Technometrics $10,1-11$.

Langer, G., Schonbeck, G., Koinig, G., Lesch, O. \& Schussler, M. (1979). Hyperactivity of hypothalamic-pituitary-adrenal axis in endogenous depression. Lancet ii, 524 .

Leach, C. (1979). Introduction to Statistics. A Non-parametric Approach for the Social Sciences. Wiley: Chichester.

Mason, J. W. (1968). A review of psychoendocrine research on the pituitary-adrenal cortical system. Psychosomatic Medicine 30,

Meltzer, H. Y. \& Fang, V. S. (1983). Cortisol determination and the dexamethasone suppression test. Archives of General Psychiatry 40 ,
501-505.

Mendlewicz, J., Charles, G. \& Franckson, J.M. (1982). The dexamethasone suppression test in affective disorder: relationship to clinical and genetic subgroups. British Journal of Psychiatry 141 ,
$464-470$.

Murray, D. (1967). Cortisol binding to plasma proteins in man in health, stress and at death. Journal of Endocrinology 39, 571-591.

Nuller, J. L. \& Ostroumova, M. N. (1980). Resistance to inhibiting effect of dexamethasone in patients with endogenous depression. Acta Psychiatrica Scandinavica 61, 169-177.

Peselow, E. D., Goldring, N., Fieve, R. R. \& Wright, R. (1983). The dexamethasone suppression test in depressed outpatients and normal control subjects. American Journal of Psychiatry 1 Ad

Platman, S. R. \& Fieve, R. R. (1968). Lithium carbonate and plasma cortisol response in the affective disorders. Archives of General Psychiatry 18, 591-594.

Reus, V. I. (1982). Phuitary-adrenal disinhibition as the independent variable in the assessment of behavioural symptoms. Biological
Psychiatry 17, 317-326.

Sachar, E. J. (1967). Corticosteroids in depressive illness: II. A longitudinal psychoendocrine study. Archives of General Psychiatry
17, 554-567. $17,554-567$.

Sachar, E. J., Hellman, L., Fukushima, D. K. \& Gallagher, T. F. (1970). Cortisol production in depressive illness. A clinical and biochemical clarification, Archives of General Psychatry 23,
289-298.

Sachar, E. J., Hellman, L., Rofwarg, H. P., Halpern, F. X., Howard,
P., Halpern, F. S., Fukushima, D K. \& Gallog , F Disrupted 24-hour patterns of cortisol Gallagher, T. F. (1973). depressives. Archives of General Psychiatry $28,19-24$ psychotic Shulman. M. B \& Dicwol

suppression test in patients with). A two-dose dexamethasone Psychiatric Association Joumal 22,417 chiatric illness, Canadian Spar, J. E. \& Gerner, R (1082). Does $417-422$.

test distinguish dementia from depression Psychiatry 139, 238-240.

Spitzer, R I Fndicots J criteria. Rationality and reliability, E. (1978). Research diagnostic 35, 773-782.

Stokes, P. E., Stoll, P. M., Mattson, M. R. \& Sollod, R. N. (1976)
Diagnosis and psychopathology in psychiatric pation dexamethasone. In Hormones, Behaviour, and patients resistant to E. J. Sachar), pp. 225-229. Raven Press, and Psychopathology (ed. Suwa, N., Yamasita I 229. Raven Press: New York

Y., Asano, Y. \& Fujieda, T (1074). Ciraki, F., Okada, Y, Saito cortisol in endogenous (ed. N. Hatotami), pp. 4-12. S. Karger: Basel (etam), pp. 4-12. S. Karger: Basel

Targum, S. D., Sullivan, A. C.\& Byrnes, S. M.(1982). Neuroendocrine interrelationships in major depressive disorder. American Journal of Psychiatry $139,282-286$

Wilens, T. E., Arana, G. W., Baldessarini, R. J. \& Cremens, C. (1983). Comparison of solid-phase radioimmunoassay and competitive protein binding method for postdexamethasone cortisol levels in psychiatric patients. Psychiatry Research 8, 199-206

Wing, J. K., Cooper, J. E. \& Sartorius, N. (1974). The Measurement and Classification of Psychiatric Symptoms. Cambridge University Press: Cambridge

Wing, J. K., Mann, S. A., Leff, J. P. \& Nixon, J. M. (1978). The concept of a 'case' in psychiatric population surveys. Psychological Medicine 8, 203-217.

Winokur, G. (1979). Unipolar depression: is it divisible into autonomous subtypes? Archives of General Psychiatry 36, 47-52.

Wood, K., Harwood, S. \& Coppen, A. (1983). Technique and accuracy of the dexamethasone suppression test. Archives of General Psychiatry 40, 585. 